Journal of Engineering and Applied Sciences 14 (Special Issue 5): 8955-8963, 2019

ISSN: 1816-949X

(C) Medwell Journals, 2019

\title{
Integration of the Product Life Cycle and Attributes Based Cost and its Reflection in Reducing Costs
}

\author{
Abdulridha Lateef Jasim, Alaa Mohammed Obaid and Khadija Jomaa Muter \\ Department of Accounting, College of Administration and Economic, Mustansiriyah University, Iraq
}

\begin{abstract}
The economic units in the competition environment face constant challenges that appear from time to time as the occurrence of competing units or similar products to the economic unit products. These units have been forced to work tirelessly to keep up with the pursuit of these developments to achieve the objectives and provide a guarantee of growth and continuity in the competitive environment. This research has been addressed the two techniques of product life cycle and attribute based costs and the reflections of this integration in reducing the unnecessary costs of the products for the economic unit. The general company for vegetable oils has been chosen as a sample to conduct the application by the researchers who have reached to a set of conclusions and perhaps the most important of these conclusions is the integration between the techniques of attribute based costs and product life cycle, which enhances the process of identifying activities and non-added attributes of values in order to evaluate them and focuses on attributes that reinforce the perceived value of the customer as well as the problems, which the vegetable oils company faces related to activities of poor design, research and development in addition to non-added activities of values that hinder the possibilities for competitive advantages.
\end{abstract}

Key words: Product cycle life, attribute based cost (costs on the basis of specifications), decline costs

\section{INTRODUCTION}

Since the last decade of the last century, the world has witnessed many rapid, dramatic developments and changes, which began to define the features of the new global order. These developments and changes covered the political, economic and social fields, in particular the remarkable development in information technology and the increased reliance on high technologies in all fields, in particular in the manufacturing environment. Moreover, major and rapid changes have been happened in the environment of modern manufacturing systems in recent years, as a result of the rapid, great and continuous technical progress in the field of information technology and the choice of advanced industrial technologies led to tremendous changes in the quality of activities and methods of their performance, cost of their structures and in the methods of their monitoring as well as the emergence of many technical methods that rely on these advanced industrial technologies through the stages of the product life cycle. The competitive determinants of industrial companies are to reduce the cost of their products and the quest of possessing the fore and lead to decline costs in the market or society, which final outcome is to achieve reasonable and sufficient rates of profitability for their survival and continuation and this leads to find a new appropriate investment climate and fulfills the competitive advantage over its competitors.
Each level of quality has its costs and this cost forms a great percentage of the total cost of the product, therefore several cost-effective strategies have appeared, including the attribute based cost system, which aims to determine the cost of products in light of the specifications determined by the client.

\section{RESEARCH METHODOLOGY}

Research problem: Companies face a constant pressure to reduce and manage the cost of the goods or services that they provide. The perception of tasks or activities that cause the increase in costs is useful matter in calculating and managing the cost of the products. Therefore, the problem of the research has focused on studying and analyzing of some modern cost-effective technologies and among them is the impairment of production costs as well as the maintenance of a distinct level of quality and achieves the excellence under the modern technologies to support competitiveness to meet the ambition of companies in quality, cost and performance management in order to meet the challenges of competition.

Research objectives: The main aim of the research is to shed light on positive implied effects of integration of the life cycle of product with the attribute based costs as well as knows each of these techniques and their effect in reducing costs with preserving the quality of products.

Corresponding Author: Abdulridha Lateef Jasim, Department of Accounting, College of Administration and Economic, Mustansiriyah University, Iraq 
Research hypothesis: The study is based on a basic hypothesis: Integration between the product life cycle and attribute based cost system enhances the potential for cost impairment with keeping on product quality and its characteristics.

\section{Research methodology:}

- The deductive approach, it is done through the logical sequence of recognized hypotheses and axioms in order to get conclusions that reinforce what has been adopted in the study based on reading books, university papers, periodicals and foreign researches

- The inductive method, it is done by inducting the relevant problems of study subject

Society and place of study application: The study Was applied in the general company for vegetable oils.

\section{PRODUCT LIFE CYCLE}

The recent years have been witnessed an increased interest in product life cycle accounting, due to several factors and the most important of which is the strictness of environmental laws and the competition on costs, (Kulmala, 2012).

Product life cycle concept: The traditional cost procedures are mainly focused on the manufacturing stage of the product life cycle, for costs are treated as period costs before the start of the manufacturing process, such as research, development and design, accordingly they are not included in the product cost calculations nor they are subjected to traditional accounting control procedures, (Drury, 2000). It should be noted that under the strategic approach of the cost management system, the attention will be further than this, because it includes the life cycle of the product from the beginning of research and development (R and $\mathrm{D})$ activities until the end of sales services and then the determination of product cycle cost means to track and assemble the cost of the product from the start to the end (Hilton et al., 2000).

Product life cycle classifications: It was necessary to study the product life cycle of the customer as it affects the management of the total product life cycle. There are three main standards that have the great effect on the customer's decision of buying the product:

- Product quality

- Purchase price of the product

- Factors related to time (product availability throughout its life cycle period)

Then, the product life cycle takes into account of the production life cycle cost and sales life cycle.

Product life cycle cost: The product life cycle cost is intended to track and collect the costs associated with each product from the beginning of research and development activities to the final customer's service activity as in Fig. 1.

It is noted in Fig. 1 that, product life cycle cost has three basic stages, which are the costs before the production process represented in research, development design and production costs, as well as costs after production represented in marketing, distribution and final customer's service, where the management cost focused on manufacturing stage of product cycle life cost, whereas, the costs of upstream production activity (pre-production process) and costs of downstream production activity(post- production process) are treated as period costs and this means that they are not included in the product cost calculations (Drury, 2000).

Product sales life cycle: It means the successive phases in the product life at the market from the beginning of introducing the production as well as growth and prosperity of sales through maturity stage and then deterioration and decay stages. The stage in which the

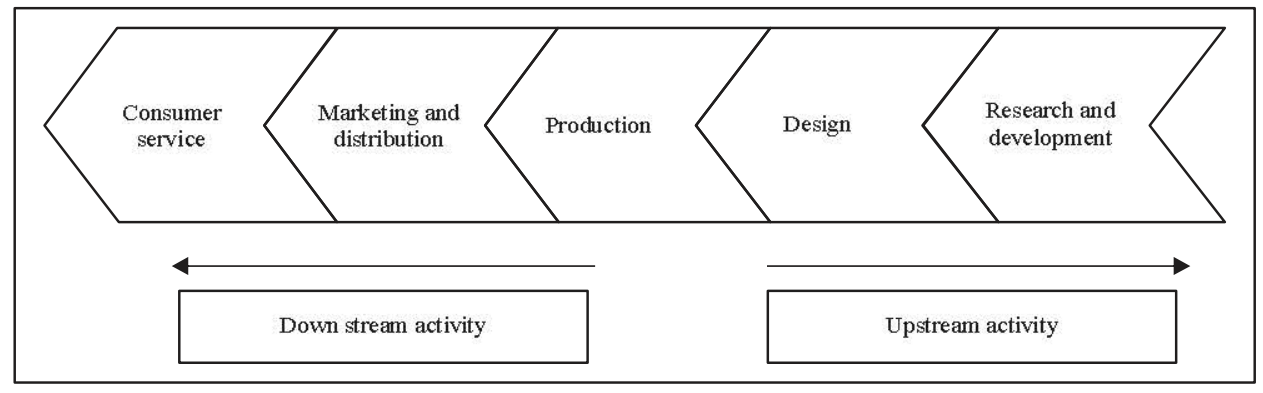

Fig. 1: Product life cycle activities Source: Blocher et al. (1999) 


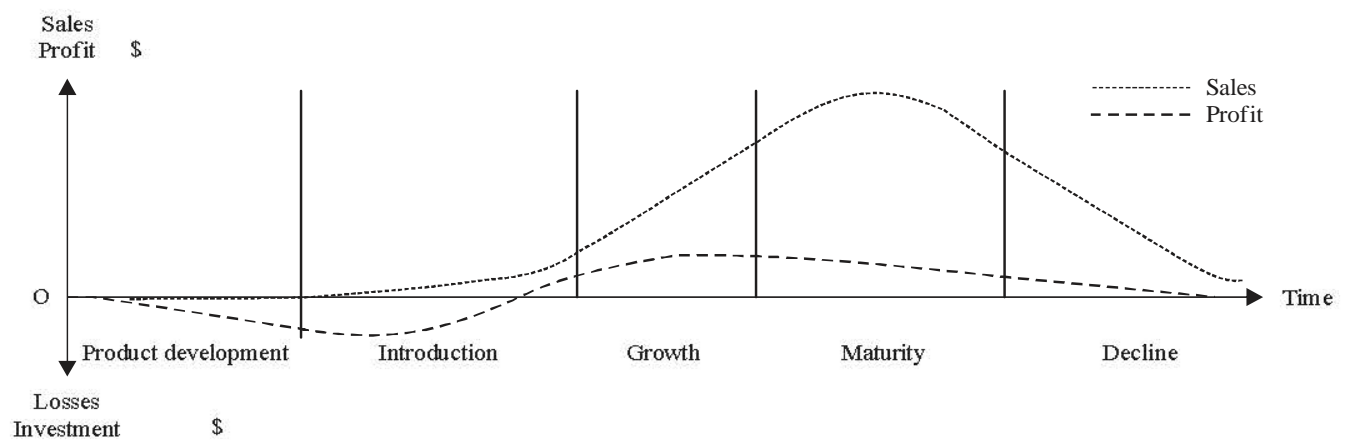

Fig. 2: Product life cycle

product is developed, it is a nursing stage of product life cycle. There are no sales in this stage but the company is preparing to provide the product for the market. As the product progresses during its life cycle, changes happen in the marketing mixture with product changes and the challenges of development as well as available opportunities. The product life cycle can be divided into several phases characterized by generating yield (revenue) of the product (Blocher et al., 1999).

Of the Fig. 2, it can say that product life cycle is a set of interrelated phases that begin with the development stage and end with stage in which the product comes out of the markets. It has been used as a tool to increase customers' satisfaction and achieve the goal of reducing the costing. Therefore, this requires coordination and compatibility between these stages. There is also intervention between product life cycle and attribute based cost system, which is considered as an organized framework for costs-reducing management, where it provides information for managing understanding and managing costs too, during the design, development, manufacture, distribution, maintenance and abandonment of the product phases and this will be explained in the third theme.

\section{ATTRIBUTES BASED COSTS SYSTEM}

Attributes based cost system concept: The concepts of attribute cost-based technology is relying on attributes (specifications), as it is known that a cost-measuring technique is based on the use of product attributes (specifications) by directly linking between costs and product attributes (specifications), (Al-Saqir, 2011). It is also a product of the company philosophy that leads to constant improvement and attention to manufacture products conforming to the attributes (specifications) determined by the customers and to collect the costs related to the customer and determine them in different cost complexes based on different types of cost drivers depended on those attributes (specifications), (Mahmoud et al., 2014). From foregoing, it is possible to say that attribute based cost technique is a cost-effective techniques (cost techniques) that adopt the specification that meets the requirements of the customer and displays the costs related to him and works to reduce them and creates a competitive advantage, it should be also provided some of the requirements for the purpose of applying the attribute based cost (Al-Saqir, 2011), which are:

- Identify the main product specifications series that meet the requirements of customers and consumers

- Determine the achievement levels for each specification of the product

- Determine the cost and return of the product at each stage of completion

\section{INTEGRATION OF PRODUCT LIFECYCLE AND ATTRIBUTE BASED COST TECHNOLOGY AND COST REDUCTION}

The integration of the two technologies enhances the potentials for reducing the unnecessary costs.

Reducing costs: Projects may be subject to a rise in costs or a decline in the level of profits from the required level due to many factors such as: The existence of bad management or untrained labor or poor distribution of these workers or an increase in advertising and training expenses and public relations (Darwish et al., 1990). In this case, it is important to study the reasons of the existence of this increase in costs and its amount and causes of its occurrence in order to begin immediately in treating them according to the priority and importance under a specified targeted cost. The reduction of costs in the absolute sense is a reduction in the total number of money and this type may be done without planning or administrative efforts such as the reason for the reduction is the reduction in the amount of production and thus the actual result is the increase of cost and not its reduction and this is not intended but is intended to reduce areas of inevitable waste and loss and disposal of those activities that do not add value, (Al-Jabr, 1997). Another author defined it as "getting more benefits (outputs) from the same resources (input) or getting the same outputs with an amount which is less than inputs" (Abu Al-Azm, 1998). 
Principles of reduction: It is necessary to consider some of the following principles and foundations in order to make the costs reduction process effectively and successfully (Al-Jabr, 1997):

- Focus first on those elements that bear the greatest cost reduction with minimal effort compared to other elements

- The study and analysis of costs and application of proposals should not be greater than cost reduction

- The reduction in costs should not lead to a reduction in quality, which would affect total revenues

- Costs reduction should not lead to take erroneous strategic decisions such as dispense from a fixed asset that may be needed in the near future

- Costs reduction should not weaken the morale of workers, which affects productivity

Factors affecting cost reduction: The constant reduction of cost by competitors has created a kind of endless search for all companies to reduce the cost of their products. This reduction focuses on two main areas:

- Keep only on those activities that add value and they are those activities that customers see adding a benefit to the goods or services that they buy

- Manage the use of engines or cost drivers for these activities that add value efficiently

The cost driver or factor is any factor that affects the cost in the sense that the change in cost driver causes the change in the total cost associated with the purpose of cost (Horngren et al., 2012).

Costs reduction by using the product life cycle and attribute based cost: It is clear that the point of convergence with the techniques of strategic cost management is the continuous improvement, whether it was by the research and development or through any approach, which enhances the availability of specifications that support and enhance the customer's requirements and thus the integration of work will be in two fields:

- Diagnosing non-added activities for values to be evaluated and excluded if it is necessary

- Supporting activities that are designed to meet customer's requirements and contribute to growth support for the product life cycle

\section{REALITY OF A COMPANY IN QUESTION AND THE NATURE OF ITS ACCOUNTING SYSTEM}

In this section, we will examine the current status of the General Company for the vegetable oils, its financial status and the types of information systems existing in the company.
A brief on the general company for vegetable oils: The general company for vegetable oil industry is one of the largest specialized companies in the country in manufacturing liquid oils, solid fats, soaps, cosmetics and cleaning powders. It was established in 1970 after the merger of the company for extracting vegetable oils, cotton seeds, Rafidain Company for the detergents industry, industrial printing company and Abu al-Hiel Company for soap in 1968-1970. It is one of the first companies to get ISO 9001: 2008 certificates. The company is working on keeping pace with the latest developments in the field of industries for all its products, it has long, high and technical experience over 70 years in this field, as well as it possess specialized laboratories and efficient and experienced staff. The company aims to contribute in supporting the national economy in the field of manufacturing solid and liquid vegetable oils, detergents, soaps, various cosmetics and other auxiliary materials and packaging to achieve the highest level of growth in work and production. It applies the principle of economic calculation and efficiency of investing public funds and their effectiveness in achieving the objectives of the state and raising the performance levels of the national economy in order to achieve the objectives of development plans. The Company carries out the following tasks and activities:

- Extracting liquid oils and manufacturing all kinds of oils, different detergents, various cosmetics, byproducts, food products, chemical and packaging materials for its purposes or for the account of others according to the approved and qualified specification or agreed specifications

- Developing and expanding current factories and production lines and establish projects and their complementary and new lines

- Purchasing and importing production materials or any materials that involve in its production or need.

- Marketing its production inside and outside Iraq

The company has several factories distributed throughout the country, namely Al-Rasheed, Al-Amin, Al-Mamoun, Al-Farabi, Imam Al-Hadi and Baiji (Al-Mansour).

Cost accounting system in the general company for vegetable oils: This system helps in the planning process, control and evaluation of production through the preparation of planning budgets, reports of monthly and quarterly performance efficiency and other reports requested by the Management and the Ministry of Industry as well as assistance in determining the costs of new products and pricing of existing products and calculating the cost of storage and preparing lists of costs to extract the cost of made production. The Cost and Budget Accounts Section performs these basic functions as well as other tasks that it performed. Moreover, it prepares the statistical reports and analyzes the cost 
Table 1: Basis (principles) of the allocation and distribution of costs components to Source: Prepared by the researchers who depend in their work on the costs section

\begin{tabular}{|c|c|c|}
\hline Guide & Account names & Allocation or distribution basis \\
\hline 31 & Salaries & Salaries lists \\
\hline 321 & Raw materials & Outbound stock document \\
\hline 322 & Fuel and oil & Equally on beneficiary centers \\
\hline 323 & Spare parts materials & Outbound stock document \\
\hline 324 & Packing material & Outbound stock document \\
\hline 3251 & Supplies and tasks & Number of employees \\
\hline 3252 & Stationery & Document constraint/number \\
\hline 327 & Water and electricity & Area \\
\hline 3312 & Building Maintenance & Area \\
\hline 3313 & Maintenance of machinery and equipment & Document constraint/number \\
\hline 3314 & Maintenance of means, transport and transmission & Equally on the number of cost centers \\
\hline 3315 & Maintenance of office furniture and equipments & Document constraint/number \\
\hline 3331 & Campaign and advertisement & Sales price rate \\
\hline 3341 & Employee's transport & Employees' number \\
\hline 361 & Debit benefits & Each center's total salaries \\
\hline 37 & Depreciations & Assets' register \\
\hline
\end{tabular}

centers. It prepares the cost balance, which distributes the costs to the productive, service, marketing and administrative centers and finally it prepares the annual financial report at the end of the year. It can be said that the work of this section is very wide, where it performs tasks other than the tasks it performs that must be assigned to another section within the company. The section performs its works manually without using any modern technology. The company uses the cost calculations associated with the unified accounting system, which divides the company into centers of cost and classifies in four main groups, namely productive cost centers, productive services centers, marketing centers and finally management centers. These centers carry Fig. 1-3 and $Z$, respectively and for each main group, there is a subset of the cost centers. The subsidiary and main groups of the cost centers are represented in the General Company for vegetable oil industry as follows:

- Production centers: The company was divided into six factories

- Production services centers: All company centers that are not related to the service of the product itself, but are linked indirectly

- marketing cost centers: These centers are marketing departments where research, marketing operations are conducted as well as outlets for discharging of company products

- Administrative cost centers: They are the financial, administrative and commercial, supervision, control, planning, follow-up and legal department and each one has its own symbol. The costs components are allocated and distributed to all centers (production, service, marketing and management) according to the bases used by the cost section, as shown in the Table 1. It is clear from what has been mentioned that the company relies on the unified accounting system of the procedures and classifications to cost components because it is one of public sector companies owned and managed by the state, but the division of the company into (6) factories, then the division of each factory on the cost centers and adopt the method of changing theory in the preparation of company costs lists, this may make easy for some to do the procedures for calculating product costs and also it provides an opportunity for the possibility of studying and evaluating each product separately and in each of its factories

Enhance specifications (attributes) that meet customer's requirements (needs) cost centers: The product is built in a series of specifications that work together or some of them contribute to create the customer's value and as follows:

- The product is integrated with a set of added specifications

- Achieving those product-related specifications requires a range of activities

- Finding those activities depends on costs achievement (realization)

- The integration of these activities and specifications will achieve the customer's value

Figure 3 shows the requirements for creating value for the customer based on what mentioned above.

The composition and creation of the value for the customer depends on the availability of specifications that meet the customer's need (requirements) and throughout the product life cycle and for the purpose of achieving what has been mentioned a separate section should be available for research and development to ensure the possibility of growth and sustainability of the product in the market, but this section is not active in the vegetable oils company and it has not a tangible role in: 


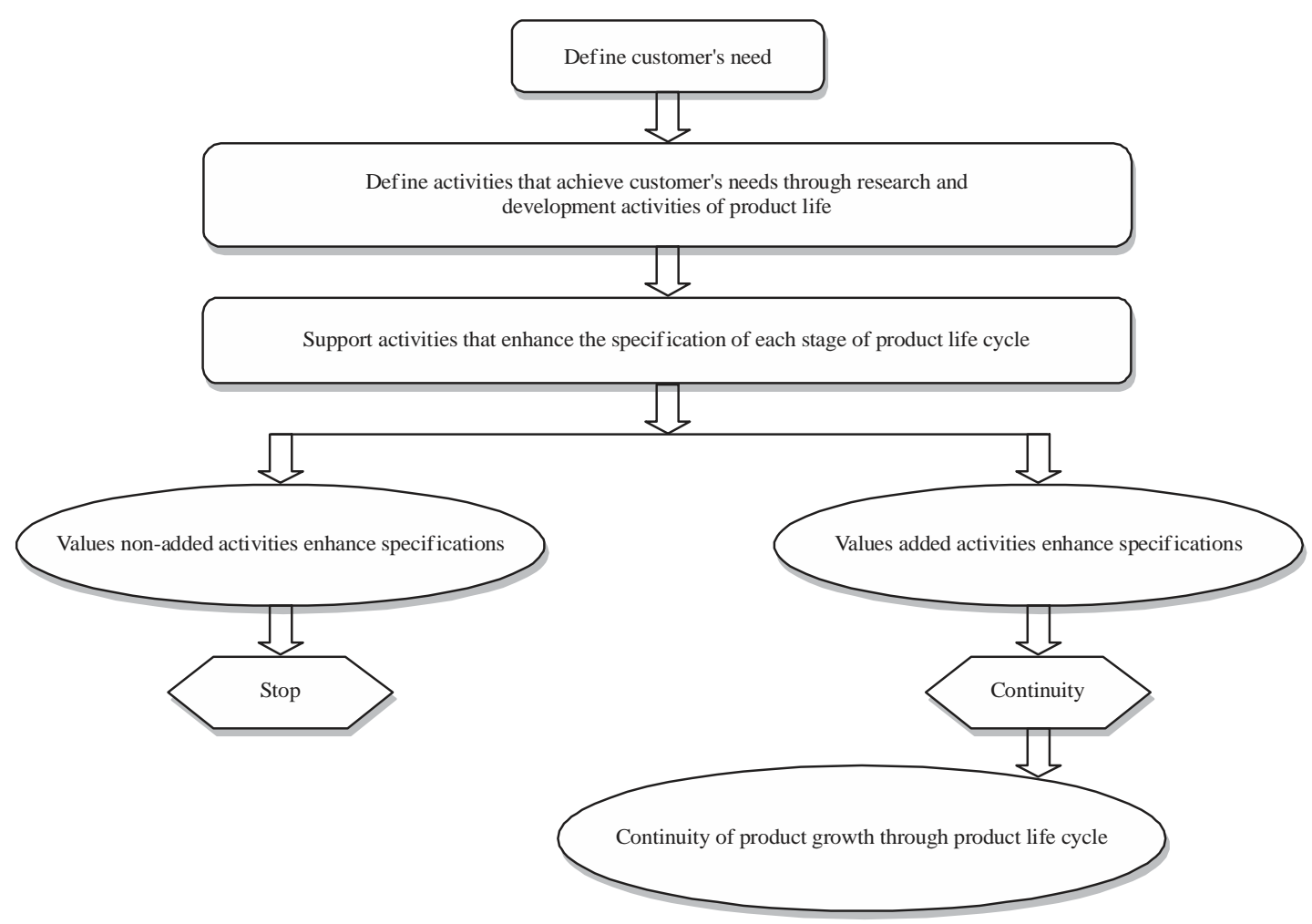

Fig. 3: Creating the value based on product specifications (attributes)

Source: prepared by the researchers

Table 2: Company activities costs due to $\mathrm{ABC}$ technique

\begin{tabular}{ll}
\hline Activity & Activity cost (ID) \\
\hline Soap activity & 262859041 \\
Active substance activity & 407709769 \\
Preparation activity & 1440637914 \\
Mixing activity & 391528891 \\
Cutting and packing activity & 1708814341 \\
Drying activity & 291123622 \\
Stores activity & 560858769 \\
Energy sources activity & 571010711 \\
Maintenance and repairs activity & 87461283 \\
Quality laboratories & 292667610 \\
Management & 1450463144 \\
Boilers unit & 178580860 \\
Total costs activities & 8426715960 \\
\hline
\end{tabular}

- Introducing new products into t competition market because of the availability of foreign product with competitive prices

- Searching for alternatives to provide local raw materials rather than import and external control

- Promoting the use of stagnant materials and industrial waste

- Continuous analysis of raw materials in order to conform them to the specifications

Based on what was mentioned, the research and development department did not carry out any activity that would support the company oils, it was necessary to examine and study all the activities in the company in order to identify the non-adding activities of the value and work towards excluding them. Table 2 shows the costs of all the activities of the company's products (soap, powders, Toothpaste, shaving cream, hand sanitizer, shampoo and sulfonic Acid) after calculating them according to cost-based activity techniques and after determining the cost guidelines associated with each activity to support the potentials for diagnosing of nonadding value activities.

It will be discussed some of the activities described in the previous table of which the two researchers believe will be the most important gradual solution to meet the requirements of research because they are considered a non-adding for the values even the case it is partly but it takes into consideration that these proposals have been presented and study with the company and the competent authorities:

- Stores activity

- Management activity

- Quality laboratories activity

Stores activity: The general company for vegetable oils has a large number of stores used for two main purposes:

- Storage of imported raw and domestic made material

- Storage of company provided products 
It is noted that the number of warehouses is large and the costs incurred by those stores are high (buildings' depreciation, guard and warehouse management) as well as the accumulated damage due to long storage periods. Then, the reduction of the number of those stores and restricting them only for imported raw materials exclusively besides the work gradually to convert those stores to central warehouses in a site serves all activities and centers, in addition to the utilization of those stores on two ways:

- Conversing these stores that will be closed to small factories within the company worked to provide raw materials that are imported from abroad and thus the costs will be reduced as well as starting to provide materials for the local market and maximizing the benefit of the company

- Conversing these stores to an integrated center for direct sales within the company's buildings and here the non-added costs of value will be eliminated non-added costs borne by the customer and enhance the customer's ability to obtain the product from the main source with the specifications represented in obtaining the product directly from the company and at a lower cost

Management activity: The company of vegetable oils contains a series of centers for managements. The company allocated for each center or activity big budget to meet expenses of those managements although this administrative structure does not provide any benefit or tangible specification to the product in order to reach to the customer, thus they can be classified as a burden borne by the customer, which enhances the possibilities of product high cost as well as the alienation of the customer and forces him to look for another product in the market.

Quality laboratories activity: As in the case of managements' activities, the proposed proposal is to reduce the number of these laboratories and to adopt a central lab that includes all the possibilities required by the activities and production lines.

Designing a framework to enhance the application of attribute based costs for the company's product life cycle: The $R$ and $D$ department is one of the active departments that take part in enhancing the product specifications by providing managements with the designs and specifications continuously to ensure that the product specifications meet the customer's need (requirements) during the product life cycle. When on looks at the activities of the $\mathrm{R}$ and $\mathrm{D}$ department in the general company of vegetable oils, it will be clear that the activities of this department are focused only on submitting an annual research plan approved by industrial research and development board but at the same time we find that coordination with production lines and the following-up of achievement and progress rates are not effective. Moreover, the company has obtained the certificates of total quality management for some of its products:

- The company headquarters, soaps and cosmetics departments in al-Mammon plant got the conformity certificate of quality management system on $18 / 12 / 2002$. The certificate was renewed on $18 / 12 / 2005$ and the certificate was renewed again to the above departments on $18 / 12 / 2008$

- The liquid detergent and shampoo department obtained the certificate on $25 / 9 / 2009$ and the work is underway to renew the certificate of quality management system in addition to the work on the rehabilitation of the detergent department at the factory

Despite the company got the certificates of specifications, but it suffers from a lot of problems as far as the specifications of its products. For the purpose of designing a model that enhances the applicability of the application, some stages will be presented according which the application of attribute based costs' requirements are available during product life cycle and taking into consideration that what is presented, is consistent with the requirements of gradual application:

Phase 1: Identifying the specifications that meet the requirements of sustainable product growth. In this stage, the focus will be on studying the main specifications of the product and analyzing them as well as activating the role of research and development activities for the purpose of adding characteristics and specifications that enhance the sustainability of the product in the competitive environment. The specifications that can be reviewed for the products of the company oils are:

- External shape (outside look): As the products of the company of vegetable oils suffer from the traditional structure and not keep up with the developments, the product will be compared to the competing products in the market

- Product durability: Although the company's products are based on raw materials that are effective and non-counterfeit, they suffer from the inadmissibility in the local market due to the availability of imported products. Therefore, it is necessary to provide technology transfer requirements and support the developing product mechanisms to enhance the competitiveness of the vegetable oils company that improve it capabilities in the local market and enter into international markets. Thus, the company shall find local standard specifications for its products to enhance its competitiveness on the national levels, as well as the international trade exchange requires the coordination with the competent international organizations in the aspect 
- Service: The company of vegetable oils provides customer's access services. But the access almost covers a narrow space of the market, which is the State Departments, if this framework has expanded to include other markets and outlets, it will be possible to develop the company's products and will be consistent with the development of outlets' volume that can be provided in the private sector, this means that company distributors can enter the market and in the same way through which they reach the customers of State Departments. This possibility will allow direct interviews with customers and identify their problems and suggestions regarding the development of the company's products. The company also suffers from the problems of not being able to complete the development program due to non-availability (the lack) of these allocations, so it would be better to rely on the private sector to provide such allocations and in a manner that ensures the meeting of the requirements of development and maintenance of the vegetable oils company. Second stage: classifying the product into a series of specifications and defining the main parts related with each specification. This stage is of great importance because the main specifications and parts of the product related to these specifications are examined and here it is necessary to consider some things and the most important of which:

- The absence of a continuous examination for the interactions in productive lines from which that the process of saponification is caused. This process is a result of the convergence of the acid element with the base one. The acid element sources depend on the nature of the product because the oils and cosmetics are depended on (corn oil, coconut oil and olive oil), while hand soaps of both solid and liquid ones depend on (corn oil, cotton oil and fish oil). These fats can be provided but the problem in the basal branch that results from complex chemical processes and these interactions suffers from the lack of accurate and continuous local follow-up to detect the points of weakness

- The absence of actual studies to exploit the untapped areas in the company to build factories within the company to provide the production requirements of raw materials instead of importing them

Phase 3: Determining the product parts cost on the basis of the specification.

Here, the specifications for each activity of the product and the cost for each specification of the product specifications should be diagnosed and the focus will be on the following approaches:
- Production-related costs: They are the direct related variable costs of the production volume, such as related raw materials of the product. These costs enhance and linked to the product's aesthetics and their conformity with specifications

- Activities-related costs: They are costs related to product activities and they can be diagnosed in direct wages element and indirect industrial costs elements. The focus in these costs is on defining the necessary time to submit product parts and specifications for study

- Energy resources-related costs: Here, the attention must be paid to the assets costs related with production and in particular production-related assets

- Non-industrial elements related costs: It represents the good episode in the series product activity specifications costs that are concerned with shape and aesthetics of final product and these costs are marketing and administrative costs

\section{CONCLUSION}

- Enhancing attribute based costs technique and economic unit possibilities in eliminate problems and deficiencies in traditional techniques

- Cost-based technology enhances the potentials of the economic unit to provide products and specifications that enhance the value that can be met by the customer

- The product lifecycle is one of the strategic cost management techniques that have a role in weighting the possibilities of product growth and its sustainability in the competitive environment, because it stems from the philosophy of meeting customer's requirements as a competitive priority

- The integration between attribute based costs and product life cycle techniques contributes in diagnosing the non-adding activities and specifications of the values for the purpose of evaluating them and focusing on the specifications that enhance the given value of the customer

- The vegetable oil company suffers from problems related to poor interest in design, research and development activities, as well as the presence of non-added activities of values that hinder the potential of achieving competitive advantages

- The possibility of designing a framework that promotes the application of attribute based costs for product life cycle in the company where the research is applied

- The scientific application of attribute based cost technology for the product life cycle proved its great ability to reduce costs that do not add value to the product 


\section{RECOMMENDATION}

- To keep abreast of the ongoing changes in the competitive environment, economic units must follow developments in costs technologies that promote competitive advantage

- The adoption of costs-based technology on the basis of specifications will enhance the potential to provide relevant information related to product specifications and its costs as well as maximizing the value of the product and customer

- To enhance the capabilities of economic units to achieve continuous growth in the competitive environment, the product life-cycle technology and its implications will continue to be effective steps to support the interest of research and development activities for the continuous improvement of product specifications and the consequent support of customer's given value

- The company shall continue its work on improving the scientific and practical rehabilitation of its employees by providing educational opportunities as well as focusing on continuing training courses and workshops

- The company shall eliminate some centers and non-added activities of values and standardize activities in a central unit to ensure the exclusion of non-added costs of values and promote activities that support the continuous improvement of the specifications of the company's products

\section{REFERENCES}

Abu Al-Azm, F.M., 1998. The role of systems analyst in reducing the costs of commercial activity. Account. J., 19: 29-30.
Al-Jabr, N.B.A.A., 1997. Towards a proposed approach for reducing costs in Saudi industrial establishments, field study. J. Financial Commer. Stud. Admin. Sci., 3: $187-188$.

Al-Saqir, M.A.M., 2011. Proposed framework for integration between the cost of specifications (ABC(II) and materials consumption accounting (RCA) for the purpose of supporting the competitiveness of the faculty. College of Commerce, Suhaj University, pp: 78-82.

Blocher, J.E., K.H. Chen and T.W. Lin, 1999. Cost Management: A Strategic Emphasis. 1st Edn., McGraw-Hill, New York, USA., Pages: 398.

Darwish, B., A.M. Said and S. Kamel, 1990. How to Improve the Cost Performance in the Saudi Business Facilities. Chamber of Commerce and Industry, Jeddah, Saudi Arabia.

Drury, C., 2000. Management and Cost Acounting. 5th Edn., International Thomson Business Press, Saudi Arabia, Pages: 890.

Hilton, R.W., M.W. Maher and F.H. Selto, 2000. Cost Management: Strategies for Business Decisions. McGraw-Hill, Boston, USA.

Horngren, C.T., S.M. Datar, G. Foster and M.V. Rajan, 2012. Cost Accounting: A Managerial Emphasis. 14th Edn., Prentice Hall, USA.

Kulmala, H.I., 2012. Cost perspectives of product development. Cos Management Center, Tampere University of Technology, Industrial Management, pp: 3 .

Mahmoud, M., F.M. Allah and Z. Fathi, 2014. Use of the cost system based on the specifications in the analysis of customer's profitability. Future Res., 45: 119-122. 